\title{
Farm to childcare: An analysis of social and economic values in local food systems
}

\author{
Jacob C. Rutz, ${ }^{\text {a* J. D ara Bloom, }{ }^{\text {b Michelle Schroeder-Moreno, }}{ }^{\text {, }} \text { and Chris G unter }}{ }^{d}$ \\ North Carolina State University
}

Submitted August 7, 2017 / Revised March 1 and June 20, 2018 / Accepted June 25, 2018 /

Published online September 12, 2018

Citation: Rutz, J. C., Bloom, J. D ., Schroeder-Moreno, M., \& Gunter, C. (2018). Farm to childcare:

An analysis of social and economic values in local food systems. Journal of A griculture, Food Systems,

and Community D evelopment, 8(3), 23-39. https:/ / doi.org/ 10.5304/ jafscd.2018.083.004

Copyright (C) 2018 by the Authors. Published by the Lyson Center for Civic Agriculture and Food Systems. Open access under CC BY license.

\begin{abstract}
Farm to institution is a component of the local food movement, representing the growing link between local producers and organizations like schools, prisons, and hospitals. These are organizations that have concentrated buying power and thus a sizable influence on local food supply chains. Farm to childcare represents a next step in

a * Corresponding author: Jacob C. Rutz, Farm to Childcare Farmer Liaison, D epartment of Agricultural and Human Sciences, North Carolina State University; 512 Brickhaven Road, Box 7606; Raleigh, NC 27695 USA; +1-513-939-6444; jcrutz@ncsu.edu

b J. D ara Bloom, Assistant Professor and Local Foods Extension Specialist, D epartment of Crop Science, North Carolina State University; 2406 Williams Hall, Box 7620; Raleigh, NC 27695 USA; dara_bloom@ ncsu.edu

c Michelle Schroeder-Moreno, Professor, Agroecology and Sustainable Food Systems, and Major Director and Assistant Director of Educational Programs for the Center for Environmental Farming Systems, D epartment of Horticulture Science, North Carolina State University; 230 Kilgore Hall, Box 7609; Raleigh, NC 27695 USA; msschroe@ ncsu.edu
\end{abstract}

farm to institution, serving young children at the apex of their habit formation and biological development, and providing economic opportunities for local farmers. Using a qualitative case study methodology in one urban county in North Carolina, this paper asks the questions: (1) How do childcare centers, farmers, and distributors negotiate the tensions between social and financial values in the farm-to-childcare initiative? and (2) What strategies do these supply chain actors use to overcome barriers? Analyzing the perceptions of participation in a farm-to-childcare project of 11 childcare centers, 11 farmers, and four distributors shows parallel values for children's health and community con-

d Chris G unter, Vegetable Production Specialist and Professor, D epartment of Horticulture Science, North Carolina State University; 230 Kilgore Hall, Box 7609; Raleigh, NC 27695 USA; cgunter@ncsu.edu

\section{Funding Disclosure}

The research for this paper was supported in part through grants from the John Rex Endowment, Southern SARE and the W. K. Kellogg Foundation. The views expressed in this paper do not necessarily reflect those of these funders. 
nections to farmers actualized in the relationships and purchase of local foods. However, marketdriven values and actions dominated the supply chain for all participants when business solvency seemed to be in opposition to central social commitments. Childcare centers and nonprofit distributors subsidized local food purchases with inexpensive, nonlocal food and grant funding, respectively. Many farmers preferred expressing social values through noncommercial activities rather than sacrificing economic viability to participate in socially oriented programs. This study suggests that achieving the social goals of farm-to-childcare programs requires creative strategies, such as coordinating sales of smaller than $\mathrm{G}$ rade A produce, purchasing from multiple local sources, and aggregating demand from multiple centers.

\section{Keywords}

Embeddedness, Marketness, Local Food Systems, Farm to Childcare, Case Study

\section{Introduction}

Farm to institution, including hospitals, schools, and childcare centers (CCCs), has garnered major attention as a next step in the local food movement to address systemic challenges in creating equitable food systems (Campbell, Carlisle-Cummins \& Feenstra, 2013; Feenstra, Allen, Hardesty, O hmart \& Perez, 2011). Local food systems are framed as providing consumers authenticity, health, tradition, and taste through socially embedded forms of food production and exchange, including farmers markets, community supported agriculture (CSA), and farm to school (F2S) programs (Allen, 1999; Feenstra, 1997). These social values of local food systems are not necessarily inherent in the scale, organizations, or theories of change often attributed to them (Allen, 1999; Goodman \& DuPuis, 2002; Guthman, 2008; Hinrichs, 2003; Winter, 2003). Instead, local food systems uphold a multifaceted and often contradictory value system that may limit food accessibility or environmentally sustainable farming practices in tandem with more equitable arrangements (Allen, 1999; D uPuis \& Goodman, 2005). D ifferent degrees of social values and market-driven activity in the local food system color the reality of how producers sell their crops, how consumers purchase food, and how farm to institution programs function (Hinrichs, 2000, Izumi, Wright \& Hamm, 2010b).

Farm to early care and education is one example of a local food initiative that attempts to bridge low-income children and local farms through a mutually beneficial market relationship. Farm to early care and education includes elements of experiential learning and environmental design, but we will focus on local food procurement within CCCs (henceforth farm to childcare, or F2CC) as a central theme and activity in this paper. (North Carolina Farm to Preschool Network, 2016). ${ }^{1}$ Farm-to-childcare programs procure local food through direct and indirect markets, including distributors, farmers, and farm stands. Local food is then served to children during meals and as part of educational programs exposing children to new foods, where food comes from, and who grows it. The majority of F2CC research focuses on the multifaceted benefits to children's health generated by educational and consistent exposure to fresh, local foods (Hoffman et al., 2016; Williams et al., 2014). However, far less research examines the "farm to" portion of the relationship; this creates a black box in the literature for how local food supply chains work in CCCs as well as what financial and social benefits exist for supply chain partners.

At both a functional and theoretical level, F2S has informed the formation of F2CC (Stephens \& O berholtzer, 2016). Y et in comparison to F2S programs, F2CC has lower barriers to entry for local farmers and more flexibility in food purchasing; furthermore, F2CC is not expected to have financially self-sustaining caféterias (Hoffman et al., 2016). Federal funding for food in many CCCs is similar to free and reduced lunches in the

\footnotetext{
${ }^{1}$ It should be noted that "childcare centers" are a specific type of care setting under the more broad definition of early care and education settings for children, which include childcare centers, licensed and unlicensed family childcare, private preschools, Head Start/ Early Head Start, state preschools, and programs through K-12 districts (Stephens \& Oberholtzer, 2016). This paper specifically observed and analyzed F2CC participating centers in the local food system.
} 
public school system, subsidizing costs for lowincome families through the Child and Adult Care Food Program (CACFP). This can open the door for centers to utilize federal funding toward F2CC related activities (Kline, 2015). The unique nature of F2CC procurement activities warrants its own body of research separate to that of F2S.

Presently, there is a gap in the literature examining the role and benefits for actors across the entire F2CC supply chain. This paper uses a case study approach to ask the questions: (1) How do CCCs, farmers, and distributors negotiate the tensions between social and financial values in the F2CC initiative? and (2) What strategies do these supply chain actors use to overcome barriers? We begin by demonstrating that F2CC is a unique but related system compared to $\mathrm{F} 2 \mathrm{~S}$, requiring an analysis of the similarities and differences between the two in relation to the local food system. Social embeddedness theories are utilized to frame the relationships in the F2CC case study in order to examine previously under-researched components of the whole supply chain and value system. Central themes that permeate our theoretical and strategic analysis include values for local food, community cohesion, and children's wellbeing, similar to findings from $\mathrm{F} 2 \mathrm{~S}$ research. Friction arose in the F2CC program when achieving social goals seemed outside the potential for a financially viable market. In the concluding section, we will explore practical strategies for implementing F2CC for each actor.

\section{Literature Review and Background}

\section{L ocal F ood in Farm to Childcare}

Present analyses of F2CC primarily focus on nutritional and educational behavioral changes for children and their parents as a central outcome of these programs (Hoffman et al., 2016; Williams et al., 2014). Farm-to-childcare meals have been found to be more nutritious than nonlocal meal service, especially in terms of fruit and vegetable servings (Gibson et al., 2014). Exposure to more fruits and vegetables, as well as increased frequency of exposure within an F2CC-style program, positively influences children's willingness to try and like fruits and vegetables (Carroll et al., 2011;
Farfan-Ramirez, D iemoz, G ong \& Lagura, 2011; Izumi, Eckhardt, Hallman, Herro, \& Barberis, 2015; Story, Kaphingst, \& French, 2006; Williams et al., 2014). The emphasis of F2CC programs on the whole eating environment shows positive perceptions from teachers and behavioral change from parents (such as purchasing local food) as a result of F2CC programming (Gibson et al., 2014). The National Farm to Preschool Survey of Early Care and Education Providers corroborates the findings that CCCs are using more local food in meals and programs, translating into greater exposure, consumption, and behavioral change (Hoffman et al., 2016; Stephens \& O berholtzer, 2016). We include this central theme of childhood wellbeing through local food-based nutrition programming in F2CC in our analysis of the values of supply chain participants.

Far less research examines the economic relationships between farmers, distributors, and CCCs engaged in F2CC programs. A handful of pilot programs have documented direct sale relationships such as on-site farmers markets and CSA-style programs (Carroll et al., 2011; Hoffman et al., 2012). Results from the 2015 National Survey of Early Care and Education Providers also indicates that local food purchases are most common directly from grocery stores, farmers markets, and individual producers compared to intermediaries (Stephens \& Oberholtzer, 2016). While current F2CC literature assumes that farmers and other supply chain businesses are economically benefitting, few studies have analyzed all perspectives of F2CC supply chain actors, contributing to a lopsided focus on the benefits and challenges to children, parents, and CCCs (Conner et al., 2012; Conner, Sevoian, Heiss \& Berlin, 2014; Izumi, et al., 2010b). The anticipated friction between ensuring long-term business solvency and achieving broad social goals for farmers and consumers through F2CC projects requires inclusion of a socio-economic theoretical analysis of this supply chain. In the next section, we will explore theories of embeddedness and marketness as our theoretical framework to structure an analysis of F2CC projects, before turning to the $\mathrm{F} 2 \mathrm{~S}$ research in this area to inform the current study and serve as a point of comparison. 
E mbeddedness and M ark etness in L ocal F ood Systems The relationships that form the F2CC supply chain can be organized into a system of interrelated values using the economic sociology theoretical frameworks of embeddedness and marketness. Social science scholars have adapted these economic theories of behavior from the works of Polanyi and G ranovetter into a critique of food system actors' perceptions and motivations (Block, 1990; Hinrichs, 2000). Social embeddedness captures the idea that economic interactions are not just a simple set of rational choices, but instead part of complex social relationships (G ranovetter, 1985; Hinrichs, 2000). Borrowing from the work of Block (1990), Hinrichs (2000) utilizes the concept of marketness to further enrich the description of the tensions between economic and social values in direct agricultural markets (Hinrichs, 2000). Marketness describes a polarization of values that juxtaposes nonprice considerations (like degree of social connectivity) against price-oriented motivations (Hinrichs, 2000; Kirwan, 2004). High levels of marketness in the agri-food system literature are often correlated with systems that value economic profits, large-scale production and/ or efficiency, and industrial models of food production (Hinrichs, 2003). In mirror opposite, the moral economy of local and alternative food is framed to favor community well-being, small-scale production, and "natural" models of food production (Hinrichs, 2003).

Local food systems are often the modus operandi of embedded food systems, purposefully incorporating social, cultural, and ecological factors into their operations in opposition to more conventional food systems that favor price and efficiency (Izumi, Wright \& Hamm, 2010a; Kirwan, 2004). However, "local" and alternative markets cannot always be equated with fair wages or internalization of ecological costs without explicit dedication to socially just causes (Allen \& Guthman, 2006; Born \& Purcell, 2006; DuPuis \& G oodman, 2005; Izumi et al., 2010a). Hinrichs critiques the assumed embeddedness of local food systems (such as farmers markets and CSAs) as spaces that privilege social connectivity to purposefully decommodify food, but which still favor and depend on a wealthy, privileged customer base to exist (Hinrichs, 2000).
Economic longevity for farmers may require a healthy but constrained dose of marketness to thrive in these self-proclaimed alternative markets (Hinrichs, 2000). Likewise, representing "conventional" as purely market-oriented obscures the level to which all food systems are socially embedded in long-term relationships and varying degrees of regional affinities (Bloom \& Hinrichs, 2010; Izumi et al., 2010a).

Farm to School as a Precursor to Farm to Childcare Because F2S is a precursor to F2CC, the literature is more robust and offers lessons to be learned for theoretically disentangling the value systems of F2CC participants as well as offering practical conclusions that relate to F2CC programs. We now outline the findings of F2S research for each major group of actors in F2S (farmers, distributors, and consumers) to highlight how these actors balance social embeddedness and marketness.

For farmers, research has shown that commercial relationships with schools have primarily constituted 5\% or less of their farming operations' total gross sales, suggesting the impetus for farmer participation in F2S is not primarily economic (Conner et al., 2014; Izumi et al., 2010b; Joshi, Izumi \& Feenstra, 2008; Low et al., 2015; O hmart, 2002; Thornburg, 2013). Instead, farmers have been found to value social benefits, like improving children's dietary habits and supporting community efforts through F2S (Izumi et al., 2010b). However, some studies suggest that despite the low economic value of sales to schools, farmers who participate in F2S programs are diversifying their markets in an attempt to reduce risk (Conner et al., 2012; Izumi et al., 2010b). Functionally, sales and logistical issues persist for farmers operating in F2S programs in part due to the low prices in this market, as well as the fact that schools require decentralized purchases, small deliveries, and have seasonal demand and under-equipped school kitchens (Izumi et al., 2010b; Joshi et al., 2008). Some outlier farmers identified by Conner et al. (2012) demonstrate that those motivated primarily by economic interests were willing to incur transactional costs, resulting in greater profitability than farmers primarily motivated by social responsibility. This suggests that for F2S to be a profitable 
market, socially motivated farmers should move beyond the idea of schools as a charity by dedicating greater resources to meeting the logistical needs of F2S customers (Conner et al., 2012). Based on these findings, we include the two central themes of social responsibility to community and economic opportunities in the subsequent analysis to analyze the perspectives of farmers taking part in F2CC.

Distributors also play a role in F2S programs, often acting as the glue that connects farmers to schools in a multitude of fashions. D istribution entities are frequently categorized as conventional broadliners or values-based supply chains to differentiate degrees of reciprocity and trust within the chain as well as degrees of local food system focus (Brayley, Clark \& Anand, 2012; Feenstra et al., 2011; Izumi et al., 2010a). Conventional broadline distributors carry a wide range of products in addition to produce, focus on wholesale purchasing, and have the goal of driving down prices to improve overall supply chain efficiency and profitability (Feenstra et al., 2011). Values-based supply chain frameworks incorporate ideals like "local," "sustainable," and "organic" into distribution activities that are often carried out by food hubs ${ }^{2}$ or other alternative agri-food actors (Conner et al., 2011; Feenstra et al., 2011; Feenstra \& O hmart, 2012; Hardesty et al., 2014). Values-based supply chains differ from conventional supply chains (and thus conventional distributors) because they intentionally serve small and midsized farms and work to communicate and share risk at every link in the chain (Stevensom \& Pirog, 2008). However, food distributors are increasingly framed as "hybridized," or delivering local foods while drawing upon the practices and resources of conventional mechanisms of food distribution (Bloom \& Hinrichs, 2011; Forssell \& Lankoski, 2015). Values in these relationships are also complex, based in economic efficiency and optimization as well as social reciprocity with regional farmers or competition with other distributors (Izumi, 2010a). As F2S programs mature and expand, distributors' participation has grown to meet the needs for scaling-up these markets in order to improve impacts for regional farmers and other supply chain participants (Christensen, Jablonski, Stephens, \& Joshi, 2017; Conner et al., 2011; Feenstra \& O hmart, 2012; Low et al., 2015). It is imperative to include the experiences of distributors in research and evaluation to understand the full economic and social impacts of F2S programs. In our analysis of an F2CC project, we include both broadline and values-based distributors to better elucidate their role in facilitating supply chains between farmers and CCCs.

School administrators and food service staff make up the final link in the F2S chain. Schools face a myriad of economic challenges, as their budgets must meet strict federal requirements to maintain low prices through competitive bidding processes while also meeting nutritional standards. In addition, schools are often required to have a financially viable, or sometimes even profitable, food service (Izumi, Alaimo, \& Hamm 2010c; Poppendieck, 2010). D espite these challenges, the values that schools receive from participation in F2S programs may largely revolve around improving children's health and interest in school meal improvement (Izumi et al., 2010c; Schafft, Hinrichs \& Bloom, 2010). School administrators and food service staff also value the community improvement aspect of F2S by supporting local food economies and building relationships with specific farmers (Izumi et al., 2010c). As a result, we explore the social values that inform CCCs' participation in the F2CC project, as well as the practical strategies they employ in order to make these arrangements financially viable.

The primacy of economic motivations in the F2S supply chain in contrast to strong valuescentric decision making between farmers, distributors, and schools remains a key issue that guides research examining actions and perspectives in F2S programs. As described earlier, CCCs are also distinct from public school systems in terms of having more entry points for farmers and more flexibility in food purchase and use. These differences mean that CCCs may have unique strategies

2 Food hubs are defined as centrally located enterprises focusing on aggregating, distributing and marketing a specific region's agricultural output (produce) to reach a variety of wholesale, retail and institutional customers (Barham et al., 2012). 
that are unavailable to $\mathrm{K}-12$ schools to overcome economic barriers in order to incorporate social values into their procurement. Therefore, while we expect to find similarities between F2S and F2CC projects in terms of the tensions between socially embedded values and market-based actions among participants in these initiatives, the logistical differences in federal procurement programs and childcare operations necessitate further examination.

\section{Methods}

Case Study C haracteristics

In this grant-funded F2CC project, a cohort of 15 CCCs received a small subsidy (based on child enrollment) to enhance local food purchases and participated in educational workshops hosted by North Carolina Cooperative Extension. This case study is based on the first year of the F2CC project from May 2015 through May 2016. Educational workshops for CCCs focused on cooking with local foods, marketing to parents, procuring local items, and teaching children about nutrition. This F2CC project also pursued partnerships with local farmers and distributors to improve relationships within the supply chain and provide business opportunities for farms in the region. Farmers and
Table 1. Childcare Research Participants and Identifiers of the Child Population for Centers

\begin{tabular}{ccc}
\hline $\begin{array}{c}\text { Child Care Centers by Range } \\
\text { of Enrollment (n) }\end{array}$ & $\begin{array}{c}\text { Average \% Children on Child } \\
\text { and Adult Care Food } \\
\text { Program Subsidy }\end{array}$ & $\begin{array}{c}\text { Average No. of Procurement } \\
\text { Options Reported for All Food } \\
\text { Purchases }\end{array}$ \\
\hline $30-59(3)$ & $57 \%$ & 2.67 \\
\hline $60-100(3)$ & $83 \%$ & 3.67 \\
\hline $101-185(5)$ & $33 \%$ & 2.6 \\
\hline
\end{tabular}

Table 2. Distributor Research Participants and Identifiers of Operation and Scale

\begin{tabular}{cccc}
\hline Distributor by Structure (n) & $\begin{array}{c}\text { Average Number } \\
\text { of Employees }\end{array}$ & $\begin{array}{c}\text { Average Years } \\
\text { in Operation }\end{array}$ & Product Extent \\
\hline Nonprofit (2) & 2 & 4 & Produce \\
\hline For Profit (2) & 100 & 46 & $\begin{array}{c}\text { Range of food and nonfood } \\
\text { products, including produce }\end{array}$ \\
\hline
\end{tabular}

Table 3. Farmer Research Participants and Identifiers of Operation and Scale

\begin{tabular}{cccr}
\hline $\begin{array}{c}\text { Farmers by Primary Market } \\
(\mathrm{n})\end{array}$ & $\begin{array}{c}\text { Farm Size Range } \\
\text { (acres) }\end{array}$ & Product Focus in General & Average Years in Operation \\
\hline Direct to Consumer (2) & $<1-4$ & Diverse mix of fruits and vegetables & 3 \\
\hline Mixed (6) & $5-515$ & $\begin{array}{c}\text { Diverse mix of fruits and vegetables; } \\
\text { small livestock; perennial fruits }\end{array}$ & 10.75 \\
\hline Distributor (3) & $750-15,000$ & $\begin{array}{c}\text { Sweet potatoes, vegetables, some } \\
\text { annual fruits }\end{array}$ & $50+$ \\
\hline
\end{tabular}


an average of 100 children per center. Farmer operation sizes were bimodal in distribution, with one group ranging from less than one to 10 acres and the other comprising larger farms ranging from 750 to over 10,000 acres. All farms focused on a profitable central market (like direct to consumer or through a distributor) but also utilized several different market channels. Participating distribution companies also exhibited a polarization by operational size. Two were small, with less than three employees, and operated as nonprofit food hubs with specific social missions to serve lowincome customers. The other two distributors (one was national, one was regional) were considered broadliners, providing produce (both local and nonlocal), paper products, and other nonfood supplies, meeting the criterion for hybrid distributors according to the definition explained previously.

\section{Case Study M ethodology}

A case study methodology was chosen to capture the complexity and exploratory nature of this emerging F2CC supply chain. A case study is a detailed examination of events that preserves the unitary character of the social object of study to exhibit the operation of a general theoretical principle (Creswell, 2013; G uest, Namey \& Mitchell, 2013). This case study was divided into two data collection steps to build rapport, develop credibility, and encourage participants to fully represent their diverse and often conflicting perspectives (Guest et al., 2013; Mack, Woodsong, MacQ ueen, Guest, \& Namey, 2005). The steps were (1) participant observations on all accessible study sites, and (2) semistructured interviews with critical informants.

The primary author conducted participant observations over single or multiple days (up to three) on 26 sites for each CCC, farm, and distributor, taking detailed field notes from experiences working in the kitchens, dining areas, and in the field. Incorporating the experience of members from these institutions--who ordinarily do not have a voice in knowledge production (including cooks, farm workers, and truck drivers) but are integral to the function of the case being studied-provided accuracy for interpreting results (G uest et al., 2013; Mack et al., 2005). Observations were used to immerse the primary author in the language and terminology of the research participants, which subsequently informed the development of interview guides and the coding process (observational notes were not coded themselves). Semistructured interviews with critical informants at all 26 sites followed the participant observation, which allowed the primary author to utilize a common interview guide while incorporating prior interactions and following emerging and unexpected themes (Creswell, 2013). Directors from each CCC were interviewed about barriers and opportunities in the local food supply chain and how they addressed serving low-income families. Farmers and distributors were questioned about their experiences and perceptions partnering with $\mathrm{CCCs}$ to provide local produce. All interviews were recorded and transcribed verbatim. Transcriptions were thematically coded by the primary author to attach and assign meaning to strings of text to organize and develop themes from the data, as described by Coffey and Atkinson (1996) and Saldaña (2009). Coding began with the development of a series of preliminary descriptive codes distilled from participant observation experiences, which were then applied to interview transcripts. These codes captured themes from the lived experience of F2CC actors, such as "connections across community," "childcare infrastructure," "individual leadership," and "personal satisfaction." A separate set of inductive codes was developed from the interviews themselves as themes arose, such as "informal networks," "role of distributors," and "local food labeling and market value." A third coding was then conducted to further analyze the interviews and relate the descriptive codes back to the theoretical concepts of embeddedness and marketness. These included codes such as "civic agriculture," "F2CC champions," and "social responsibility."

The validity and reliability of research findings were addressed in multiple ways. First, prolonged engagement with research participants through observations in multiple settings helped the researcher gain in-depth understanding of the case at hand and built rapport with critical informants to gather detailed notes (Creswell, 2013; Mack et 
al., 2005; Yin, 2009). The primary author discussed key themes derived from the analysis with members of the F2CC project administrators, as experts in the field, to provide triangulation in determining the reliability and validity of emerging results. Reporting findings using illustrative descriptions (e.g., using descriptive quotes) that allow readers to understand the case at hand contributes to clarity and visibility of central themes identified in this study (Merriam, 1995).

\section{Results and D iscussion}

This case study explored the dual nature of social embeddedness and marketness in the local food supply chain between CCCs, farmers, and distributors to identify creative strategies to make F2CC projects viable. O ur findings indicate that CCCs valued children's health and supporting small farms, operationalized by patronizing different forms of local food distribution channels. Likewise, most farmers and distributors shared similar perspectives in general of the importance of working with low-income children to improve health outcomes. However, the whole supply chain was tempered with an economic reality that required different strategies to maintain a level of marketness to operate at a basic level. Through the often conflicting socially embedded and more price-driven values, the F2CC supply chain fluctuated between addressing equity in the food system and being challenged to ensure financial viability and long-term sustainability for those involved.

\section{Childcare C enter's V alue System}

Childcare centers participated in local food supply chains as both consumers receiving products and institutions asserting strong value systems. Taking care of children is a "heart and mission" choice as one center director attested, informing the social ethic of CCC's work with low-income children and their families. Their participation in the F2CC supply chain is an actionable result of the embedded value they place in improving children's eating behaviors and improving communities writ large. Centers also expressed strong positive perceptions of the social network they formed using local food to form a relationship with farmers, improve local economies, and support like-minded entrepreneurs along the way. However, daily and structural barriers inhibited their expression of social values through local food partnerships. Frequently, strategies to overcome barriers related to cooking inexperience and proximity to markets and funding required additional reliance on market-based solutions.

Relationships informed by degrees of social embeddedness guided CCC's choice of food providers (either farmer or third-party distributor) that prioritized personal relationships over more conventional, business-oriented transactions. One director who purchased from both a farmer and a food hub commented on her desire for a personable relationship with a farmer, saying, "I was able to hear about all the options in the area and chose [farmer's name] because he was polite and had a down-home feeling." Exploring all options for procuring local food through programs like F2CC was a necessity for CCCs to develop an interest in serving local food and to develop confidence in their ability to find convenient options. Individual relationships allowed for an educational experience through face-to-face interaction when farmers participated in the center's garden activities, story times, and special events. Similar to Hinrichs' findings in regard to social embeddedness in direct to consumer markets, the direct marketing relationship reflected deeper values associated with localness for CCCs; because trusting relationships were favored, local food was pursued and perceived as fresher and better tasting, which meant that kids would be more likely to consume produce, ultimately making them healthier (Hinrichs, 2000). Thus, CCC's values for improving childhood nutrition were intimately bound up in being local food consumers. O ne director of a larger center buying from a food hub clarified her interest in buying local food by saying, "Because it is better food, less preservatives, you know none of the additives are in it, it is just healthier for the kids, and we are going to keep supporting local." Becoming educated and knowledgeable about the presence of synthetic and unwanted ingredients in food continued to increase CCC directors' buy-in to F2CC programs.

Actualizing embedded social values in CCCs 
became tenuous when structural realities inhibited the procurement and use of fresh local foods. To begin with, just the step of transitioning into serving fresh, regardless of the localness, of the product, challenged many centers because kitchen space was unfit to receive fresh foods. Because many CCCs' design was intended for frozen, canned, or prepared foods, counter space was limited, sinks could not handle soil or silt (nor fit large quantities of vegetables), and refrigerators were at capacity. Financially, centers frequently reported lack of funding for the labor associated with the preparation of fresh foods as well as for the fresh, local foods themselves. O ne director addressed her challenge to increase fresh local foods saying, "When you go to all fresh you have to have an extra cook. Y ou have to have two people full time, because it's a lot of preparation, and that's what people fail to realize." CCCs' strategies for aiding cooks included allowing teachers aids to help process foods and even have children help with simple, safe tasks (like picking basil leaves off the stem). Also, the lack of sales-orientation during mealtime (as described in the school setting) allowed for children to sample new produce in addition to lending a helping hand in the kitchen. Once new local items were available to centers, cooks struggled to learn how to purchase and prepare fresh produce in quantities and styles appropriate for children. One cook commented on her challenging experience by saying, "The first time we ordered a bushel of collards, I was like I have no idea how much a bushel of collards is! Like is it 3 leaves?...Is that enough to serve 120 kids?" Many CCCs relied on the training for cooks provided by the F2CC program to help their centers transition into fresh, local foods.

Centers expressed an interest in supporting local businesses financially in order to support the person and social values behind the product; as one director commented, "That [F2CC] wasn't something I even thought about, but once I did, and I had rapport with [farmer], I spread his name around because he is a local entrepreneur like myself." Not only was the director weaving a relationship between the center and the farmer, but also further integrating the farmer into the larger childcare community and opening the door for a larger market opportunity. In this way, the value for local food transcended simply buying a quality product and became more about relating to the farmer. Buying local food from a farmer fit into a selective patronage that favored small, new, and minority-owned farms and their narratives. Elevating these stories in the local food system became an extension of CCCs' social interests. One director linked African American heritage to her center's food procurement strategy, explaining,

One thing for me is that the farmer we had was African American, and the majority of the children we serve are African American, too. I thought that it was very important for them to see someone that looks like them that is doing something with food.

As a market exchange for this center, F2CC represented a means to infuse social justice, authenticity, and community into the lives of both the children in the center and their larger community. Partnering with a local farmer was perceived as providing an emotional and social benefit to the children in the CCC (and presumably the farmer and director) beyond what they had derived from previous procurement sources.

From the childcare perspective, the ideological antithesis to these highly embedded social markets were more conventional or hybrid distributors. When CCCs expressed their most idealized versions of local food, mainstream food products were often portrayed as less trustworthy and large corporations as unaligned with local food values. $O$ ne childcare director of a nonprofit center commented, "I know they're in business to make money, but larger corporations are in the business to make a lot of money. So they charge what the market demands, and you know we have to pay it." The interest to pair with organizations that shared similar values (health-oriented, local-focused) and operated at a similar scale (small size) encouraged partnering with nonprofit food suppliers (food hubs), charitable farmers, and other CCCs. A number of franchise centers began to experiment with creative logistical arrangements, pooling their demand and having teachers or directors distribute food from a centrally located childcare center. 
D espite their ideological resistance to supporting large-scale distributors, the participation of CCCs in local food systems was dependent in part on their maintained patronage of broadline vendors. Because fruits and vegetables only make up a portion of CCCs' food budgets, the ability to financially express embedded social values for local food was predicated on a relationship with the conventional market. In this way, local foods were subsidized by cheaper, industrial products, and social values that were expressed verbally were balanced by the marketness displayed through actions and budget sheets. O ne center director hinted at the reality of investing more time and energy in local fruits and vegetables compared to the rest of the meal by saying, "So I may spend a little more on fresh fruits and vegetables here but I know how to go out and find a sale on rice and toys and other things." The complex value system CCCs held for food and the resulting markets they pursued were deeply enmeshed in both idealized forms of business transactions and their daily monetary realities.

Farmers' V alues in Partnering with C hildcare C enters The local food supply chain from farmer to CCC in this case study was complex, yet nascent, spanning multiple avenues for product and financial exchange. Farmers expressed a spectrum of values that motivated their interest in supplying food to CCCs (through direct or intermediated means), from market-based incentives to a more socially embedded rationale. These values were not divided into a polarized dichotomy, but varied in relationship to their size and primary focus to achieve their own basic goals.

Some farmers in this project made efforts to reflect socially embedded values within the context of their market-based relationships. Smaller farms with direct connections to end consumers often used their time to be educators and used their farms as an educational space by inviting CCCs to experience the farm. This allowed the farmers to build trust and increase the possibility of establishing a market relationship. Some farmers specifically hoped to help children, as one mediumsized farmer who sold to CCCs through a nonprofit food hub said, "It's important to me for kids to be able to see me as a farmer and also be able to have produce that's fresh, that's right next door to them." Despite interest from a majority of farmers in this study to partner with CCCs, those that engaged in a direct sales relationship with the childcare market itself were unable to sustain a viable profit (all but one farmer involved in this project abandoned direct sales to CCCs). Farmers expressed that selling to centers was a challenging experience; while they felt that their product was desired, the low volume and infrequent purchases were not sustainable for their bottom line. For the four farmers that started and stopped a direct sale with CCCs, all expressed that profitable sales were a precursor to the social investments (such as teaching children or helping in the garden) that CCCs expected. D espite the challenges for individual farmers, aggregation services, such as food hubs, provided the sense of social connection that CCCs desired while being able to handle the variability in purchasing quantity and frequency. We explore this distribution model and its potential to act as a viable alternative to provide social experiences and financial viability to F2CC projects in the next section.

Similarly, connecting through personable mechanisms and providing the educational experiences for children desired by CCCs was unfeasible for all producers in this study due to time constraints, farm location, and the scale of sales for larger farms. Instead, these farmers' social embeddedness often manifested more materially, such as donating surplus produce to charity. Gleaning the fields or donating boxes of sweet potatoes to a food bank allowed farmers to provide for lowincome people through their own infrastructure and excess while maintaining a clear and efficient line between business and charity. CCCs were outside of these charitable networks that primarily served individuals and families through the emergency food system. Another farmer in this project, whose primary market consisted of selling tractortrailer loads of produce to national or regional distribution companies, expressed a desire to "stay grounded" in his community by selling small boxes of produce to individuals, despite making little or no money from this activity. In this way, large-scale farmers demonstrated socially 
embedded values without disrupting their main market channels.

These examples demonstrate that, although farmers reflected socially embedded values, they still often prioritized marketness over social embeddedness. One small farmer who partnered with a food hub grappled with the dual expectations of providing an embedded market experience for customers and maintaining economic viability, saying,

When you're running any business, you got to stay true to your focus so that you can be profitable and be sustainable, right? There are a lot of people that are passionate about getting good food to children, schools, and daycares and whatnot. It's not something that I would be good at. It's not something that I have a passion about. I have a passion about farming.

Although some farmers in this project expressed their "passion about farming" through a socially oriented agenda that included farm visits and educational experiences for CCCs, this farmer maintained a level of marketness to prioritize financial viability. She directed her energy toward higher volume markets through food hubs and higher margin sales directly to restaurants, limiting the reciprocity with low-income consumers to maintain a level of market success. Tangential goals in children's health issues were peripheral and relegated to others that were passionate about helping children in schools and childcare. Health-oriented service providers, such as related nonprofits, Cooperative Extension, and Smart Start programs, were more strategically and financially oriented than farmers to serve the nonprocurementoriented needs of CCCs.

The transactional distance between larger farmers and CCCs in this study also inhibited a level of community connection and trust, which are understood as hallmarks of the local food system. At the same time, these farmers provided an affordable and convenient local food option for CCCs. All local farmers in this study who sold primarily through a distributor (see Table 3) were unaware that their products were consumed in
CCCs. O ne farm that sold local sweet potatoes via distributor networks was asked, "D o you know your product is used in a childcare center?" and the sales representative for this farm responded,

No, to be quite honest with you. The only reason we would know that is if they were buying from us direct and at a larger volume, and typically a childcare facility is not going to use the type of volume that would have us ship directly there.

Farmers of all sizes prioritized their customers first. This means larger farms prioritized brokers, distributors, and retailers. Communication about farm values in websites and handouts focused on issues that are important to larger distributors, such as product tracking services or international food safety certifications. For these farmers, their efforts to foster trust with customers consisted of implementing institutionalized mechanisms of promoting transparency, such as food safety certifications, rather than prioritizing social values for community relationships. At the same time, these larger scale farmers often sell to grocery stores, which is an outlet frequented by CCCs that purchase small quantities of food. Therefore, expanding local food access in markets where large farms operate, such as grocery stores, provides another avenue for CCCs to connect with local food options.

D istributors' V alues in Partnering with Childcare C enters and L ocal F armers Distributors were the main contact for many relationships in the F2CC supply chain in this case study. Distributors acted as both creators and mediators of social values, communicating with both ends of the supply chain. For-profit distributors focused on the common mantra of "the customer comes first" by prioritizing low prices. Some larger farmers were specifically pursued by large-scale distributors in an attempt to source more local produce, which was used as a marketing tool. More socially oriented distributors, like nonprofit food hubs, committed to social agendas by focusing on sourcing products from small and minority-owned farmers in tandem with providing low-income institutions with local foods. However, 
attending to the individual needs of those who struggled to participate in the market economy perpetuated an unsustainable dependence on grantbased funding for food provisioning through these food hubs. The challenge to serve both farmers and CCCs as partners manifested across these different scales, missions, and values held by distribution businesses.

Large, nationally operating distributors in this study (hybrids) approached local food procurement similarly to CCCs-- that is, as a singular but embedded component of their overall food procure ment strategy. For these distributors, local food was a strategy for marketing and developing a customer base, even without the socially embedded components of reciprocity and low-income consumer access. These distributors sourced local food when it was possible, and sometimes when it was less than ideal. As the regional hybrid distributor put it, "Buying local does not help our bottom line; but we do it because we think it's the right thing to do." At this one distribution company, the embedded social value for supporting local farmers was part of a "culture"; yet they also did not "just eat the price of local produce because it's local." Instead, market sensibilities guided their supply base to source from local first, and national and international suppliers to fill in the gaps. In fact, integrating local and nonlocal items helped distributors maintain the patronage of CCCs who valued the ability to purchase local food at low prices, allowing them to partially invest in local farms while still maintaining their bottom line. CCCs were able to leverage the growing recognition of local as a marketing tactic by specifically requesting local whenever possible, helping to drive demand beyond passively receiving local food when it was most convenient for a distributor.

On the other end of the spectrum, food hubs in this case study demonstrated embedded social values surrounding local foods both in their central goals and their communication to CCCs about the value of the farmer relationship. O ne food hub director used the concept of value-chains derived from the work of Stevenson and Pirog (2008) to emphasize the necessity of connectivity in the whole food system, saying, "I don't think it's impossible to serve both the farmer and the eater in one value chain... An ideal system is one where farmers are making a living, and eaters are eating fresh local food." As a food hub, mediating the value for local food between supplier and consumer fulfilled CCCs' value of personable relationships and farmers' need for committed customers. However, focusing on a dual social mission of addressing food security for low-income customers and providing stable pay for small and minority farmers challenged the capacity of food hubs to provide a sustainable food distribution model in the larger economy. The food hub director who framed her work as a "values-based" supply chain continued to ruminate on the friction of serving both ends of the chain, saying,

If we changed our markup a little bit and increased it, we could break even at 1.5 million, but that would mean charging more for food, which a lot of the programs that we're currently working with may not be able to afford. It also takes away more dollars from the farmer...can we do everything we want to do, is it impossible to serve both farmers and eaters at the same time?

Operationally, food hubs were more challenged than the hybrid distributors to maintain a fiscally viable relationship with CCCs due to the smaller order sizes and fragmented ordering dates. For example, the food hub provided small quantities of novel local produce so that CCCs could offer taste-tests with children. However, they did not frequently charge for this service; instead, they wrapped it into the food hub's central mission to provide access and exposure for children to new foods and subsidized it through grant funding. While this food hub director expressed that CCCs "may not be able to afford" fresh local foods, many centers were working towards procuring both small, experimental orders (like Brussels sprouts) and consistent, sizable produce purchases to support participants in the values-based supply chain.

One farmer that worked with food hubs commented on the challenge to provide affordable food options to low-income customers, saying, 
So how does the [food hub] advocate for the small farmer when they have a huge mix of conventional and organic small guys? I know they do pad the pricing... They have grant money for that. But that is certainly not sustainable, you know what I mean? You're just facilitating this idea that food is cheap instead of necessarily costing.

Socially embedded food systems at the individual actor level facilitate the intended good of these markets-- keeping food dollars local, investing in small farms, and supporting sustainable production. Taking a more protracted look, marketness in local food systems becomes necessary to ensure business solvency, since the embedded systems, in fact, do not solve the issues facing small farmers but instead perpetuate an illusion "that food is cheap." However, CCCs and food hubs operating as nonprofits explicitly aim to improve childhood health and local farm viability, which are values outside a market solution. The grants and nonprofits that distort the unfettered market by supporting food system initiatives are how many low-income customers gain access to similar nutritious products available to a well-resourced customer base. Creatively using grant funding and state or nationally funded programs (like the CACFP) to help offset the cost of F2CC programs is a strategic component of reworking the local food system to benefit farmers, distributors, and children.

\section{Conclusions}

This case study provides insight into the tensions inherent in socially embedded food systems as they operate in a highly market-oriented world. The bounds of this one case in an F2CC supply chain limit broad generalizations to all local food systems or F2CC projects. Instead, they highlight patterns of how projects negotiate values and needs between different actors. Social embeddedness theories and evidence from the F2S literature illustrate the motivations actors express throughout the F2CC supply chain. Their motivations paint a picture of community investment through a commitment to seemingly altruistic missions that cannot be explained through rational self-interest alone. Marketness concepts help explain the extent to which business-oriented decision making remains central to the actualized value system of these actors. Farm-to-childcare projects are organized around providing social benefits to supply chain actors; yet, the realities of making them sustainable require a stronger dedication and understanding of the financial needs of those involved. The small subsidy and the education and technical assistance that CCCs received through this project to overcome market barriers did not resolve outstanding challenges to connect low-income consumers and small farms. Instead, a more integrated approach to F2CC utilizing marketbased approaches, values-based supply chains, education, and other creative strategies holds promise for future programs.

Compared to F2S, F2CC demonstrates many similarities and some differences, especially for CCCs. Farmers and distributors participated in the F2CC program to express a social commitment towards children's health and exposure to new foods, often without significant or consistent economic compensation, a similar finding in the F2S literature (Conner et al., 2012; Izumi et al., 2010a, 2010b; Thornburg, 2013). Distributors in F2S also often prioritized buying locally as a means to symbolically support their regional economy or struggling farmer communities (Izumi et al., 2010a; Schafft et al., 2010). Childcare centers are markedly similar to schools, both in their socially embedded values for supporting local farming economies and educating children while also facing economic constraints. However, CCCs differ from schools in their scale of procurement and their lower pressure for profitability in meal service. Despite the yearround demand for local foods, the small, decentralized nature of childcare further reduced order sizes from food suppliers compared to schools. Childcare center's relatively small size allowed for nimble, informal purchases from a variety of local outlets, opening the possibility for viable relationships with farmers markets, grocery stores carrying local products, and even local produce stands. Smaller purchases also fit into the varied schedules of directors and/ or teachers, allowing them to stop at a farmers market on the way home from work or a grocery store on the way to work. This ultimately diminished logistical barriers to procuring local 
foods. Those centers that did prioritize a single local food market participated as members of a values-based supply chain by committing to purchasing regularly and consistently, helping pull local food through the supply chain instead of passively receiving it when available. Childcare services also do not have the burden of selling food to children in the same way schools often must; the age of the children and organization of centers allow for a single menu to be served centerwide (see Poppendieck, 2010 for in-depth analyses of school lunch financial constraints). Creative educational opportunities--e.g., teaching children to help process fresh, raw produce or exploring all available local food markets-- helped to also diminish internal barriers facing F2CC. The different structure of childcare food programs compared to $\mathrm{K}-12$ schools suggests F2CC procurement programs focus on both supporting diverse regional food market options and aggregating demand from multiple, proximate CCCs.

Childcare centers, farmers, and local food advocates can improve the function of F2CC initiatives by adapting institutional policies and practices to fit with local food realities. Childcare centers can diminish internal challenges by providing technical assistance, in partnership with county services like Cooperative Extension, to cooks as extra training for processing raw, fresh produce. Also, by collaborating with nearby centers, groups of childcare providers may be able to aggregate demand aiding in delivery for a food distributor or in their own pickup logistics. Farmers may also find a strong market for off-grade produce, since lower prices and the potential for self-processing (small children primarily consume finely chopped and/ or cooked foods) is useful to CCCs. Local food advocates and CCCs can petition mainstream food providers to continue the hybridization of the food supply so that local food is more readily available through mainstream markets, such as at grocery stores and through distributors. Overall development of local food infrastructure--through food hubs, grocery options, and farmers markets--all have the potential to be accessed by CCC consumers.

Limitations to the current study include generalizability, type of data collected, and the length of the study. The F2CC project studied was based on a single program in one urban county in North Carolina, limiting the generalization of the findings to other F2CC programs or different geographic extents. Additional data that may have informed the results, such as money received or spent on local food transactions, was not possible to collect. Also, the short timeline of data collection did not allow for measuring the effect due to grant funds received by the CCCs, or follow-up to see if CCCs who participated in the first year of the project continued to purchase local products after the discontinuation of the subsidy. D espite limitations, this research provides critical insights into the function of F2CC programs and provides suggestions for further inquiry into similar projects.

Future research in F2CC and other farm to institution programs could explore new topics relevant to all members of the supply chain. Farmto-childcare research could move beyond an initial snapshot of the function and values central to local food supply chains to focus more directly on local food economics, program sustainability, and informal F2CC networks. Quantifying the changes due to grant funding F2CC activities would provide insight into the lasting impact that similar programs could have on local food economies. Comparisons between urban and rural counties' utilization of CACFP funding in F2CC procurement practices and nonfinancially incentivized programs may provide a new perspective on F2CC's efficacy within the broader childcare industry. The role of CCCs as logistical coordinators amongst informal networks of providers may also provide a novel opportunity for farm to institution researchers. Focusing research more specifically on the ability of farmers to capitalize on nascent F2CC markets-- such as selling off-grade or small produce to CCCs-would provide insight into the viability of similar programs. Likewise, investigating the role of distributors in accessing sources and markets for local food that match existing infrastructure and business models would contribute to the F2CC discussion. With the growth in F2CC programs nationwide, a thorough and intersectional research agenda may provide new perspectives in local food practice, theory, and policy. 
Journal of Agriculture, Food Systems, and Community Development

ISSN: 2152-0801 online

https:/ / www.foodsystemsjournal.org

\section{Acknowledgments}

The authors would like to thank North Carolina

State University's College of Agricultural and Life

Sciences for their support of this project. The authors are also grateful to all of the farmers, distributors and child care centers who spent countless hours of their time sharing their knowledge and expertise.

\section{References}

Allen, P. (1999). Reweaving the food security safety net: Mediating entitlement and entrepreneurship. A griaulture and H uman V alues, 16(2), 117-129. https:// doi.org/ 10.1023/ A:1007593210496

Allen, P., \& Guthman, J. (2006). From "old school" to "farm-to-school": Neoliberalization from the ground up. A griculture and H uman V alues, 23(4), 401-415. https:/ / doi.org/ 10.1007/ s10460-006-9019-z

Barham, J., Tropp, D ., Enterline, K., Farbman, J., Fisk, J., \& Kiraly, S. (2012). Regional food hub resource guide. Washington, D .C.: U.S. D epartment of Agriculture, Agricultural Marketing Service. https:/ / doi.org/ 10.9752/ MS046.04-2012

Block, F. (1990). Postindustrial possibilities: A critique of economic disourse. Berkeley. University of California Press.

Bloom, J. D ., \& Hinrichs, C. C. (2010). Moving local food through conventional food system infrastructure: Value chain framework comparisons and insights. Renewable A grialture and Food Systems, 26(1), 13- 23.

https:/ / doi.org/ 10.1017/ S1742170510000384

Bloom, J. D ., \& Hinrichs, C. C. (2011). Informal and formal mechanisms of coordination in hybrid food value chains. Journal of A griculture, F ood Systems, and Community D evelopment, 1(4), 143-

156. https:/ / doi.org/ 10.5304/ jafscd.2011.014.016

Born, B., \& Purcell, M. (2006). Avoiding the local trap: Scale and food systems in planning research. Journal of Planning E ducation and Research, 26(2), 195-207. https:/ / doi.org/ 10.1177/ 0739456X 06291389

Brayley, D ., Clark, K., \& Anand, M. (2012). Produce distribution practices: Incorporating locally grown produce into N ew E ngland's institutional food system. Retrieved from https:/ / www.farmtoinstitution.org/ sites/ default/ files/ imce/ uploads/ 4Produce\%20D istribution\%20Practices\%202012.pdf

Campbell, D., Carlisle-Cummins, I., \& Feenstra, G . (2013). Community food systems: Strengthening the research-topractice continuum. Journal of A griculture, F ood Systems, and C ommunity D evelopment, 3(3), 121-138. https:// doi.org/ 10.5304/ jafscd.2013.033.008

Carroll, J. D., D emment, M. M., Stiles, S. B., D evine, C. M., D ollahite, J. S., Sobal, J., \& Olson, C. M. (2011). Overcoming barriers to vegetable consumption by preschool children: A childcare center buying club. Journal of H unger \& E nvironmental N utrition, 6(2), 153-165. https:/ / doi.org/ 10.1080/ 19320248.2011.576207

Christensen, L. O., Jablonski, B. B. R., Stephens, L., \& Joshi, A. (2017). E conomic impacts of farm to school: Case studies and assessment tools. Retrieved from http:// www.farmtoschool.org/ Resources/ EconomicImpactReport.pdf

Coffey, A. J., \& Atkinson, P. A. (1996). M aking sense of qualitative data: C omplementary research strategies. Thousand O aks, CA: SAGE.

Conner, D . S., Nowak, A., Berkenkamp, J., Feenstra, G. W., Van Soelen Kim, J., Liquori, T., \& Hamm, M. W. (2011). Value chains for sustainable procurement in large school districts: Fostering partnerships. Journal of A griaulture, F ood Systems, and Community D evelopment, 1(4), 55-68. https:/ / doi.org/ 10.5304/ jafscd.2011.014.005

Conner, D ., King, B., Kolodinsky, J., Roche, E., Koliba, C., \& Trubek, A. (2012). Y ou can know your school and feed it too: Vermont farmers' motivations and distribution practices in direct sales to school food services. A griculture and H uman V alues, 29(3), 321-332. https:/ / doi.org/ 10.1007/ s10460-012-9357-y

Conner, D ., Sevoian, N., Heiss, S. N., \& Berlin, L. (2014). The diverse values and motivations of Vermont farm to institution supply chain actors. Journal of A gricultural and E nvironmental E thics, 27(5), 695- 713. https:/ / doi.org/ 10.1007/ s10806-013-9485-4

Creswell, J. W. (2013). Q ualitative inquiry \& research design: C hoosing among five approaches (3rd ed.). Thousand O aks, CA: SAGE.

DuPuis, E. M., \& G oodman, D . (2005). Should we go "home" to eat?: Toward a reflexive politics of localism. Journal of Rural Studies, 21(3), 359-371. https:/ / doi.org/ 10.1016/ j.jrurstud.2005.05.011 
Farfan-Ramirez, L., Diemoz, L., G ong, E. J., Lagura, M. A. (2011). Curriculum intervention in preschool children: Nutrition matters! Journal of N utrition E ducation \& Behavior, 43(4), S162-S165. https:/ / doi.org/ 10.1016/ j.jneb.2011.03.007

Feenstra, G. (1997). Local food systems and sustainable communities. A merican Journal of A lternative A griculture, 12 (1), 2836. https:/ / doi.org/ 10.1017/ S0889189300007165

Feenstra, G., Allen, P., Hardesty, S., O hmart, J., \& Perez, J. (2011). Using a supply chain analysis to assess the sustainability of farm-to-institution programs. Journal of A griculture, Food Systems, and C ommunity D evelopment, 1(4), 6985. https:// doi.org/ 10.5304/jafscd.2011.014.009

Feenstra, G., \& O hmart, J. (2012). The evolution of the school food and farm to school movement in the United States: Connecting childhood health, farms, and communities. Childhood 0 besity, 8(4), 280289. https:/ / doi.org/ 10.1089/ chi.2012.0023

Forssell, S., \& Lankoski, L. (2015). The sustainability promise of altemative food networks: An examination through "alternative" characteristics. A griculture and $\mathrm{H}$ uman V alues, 32(1), 63-75. https:// doi.org/ 10.1007/ s10460-014-9516-4

Gibson, C. A., Harvey, S. P., Spaeth, K., Sullivan, D. K., Lambourne, K., \& Kunkel, G. H. (2014). Farm to school, school to home: An evaluation of a farm to school program at an urban core Head Start preschool program. Journal of H unger \& E nvironmental N utrition, 9(3), 334-349. https:/ / doi.org/ 10.1080/ 19320248.2014.929540

Goodman, D ., \& D upuis, E. M. (2002). Knowing food and growing food: Beyond the production-consumption debate in the sociology of agriculture. Sociologia Ruralis, 42(1), 5-22. https:/ / doi.org/ 10.1111/ 1467-9523.00199

Granovetter, M. S. (1985). Economic action and social structure: The problem of embeddedness. The A merican Journal of Sociology, 91(3), 481-510. https:// doi.org/ 10.1086/ 228311

Guest, G., Namey, E. E., \& Mitchell, M. L. (2013). Collecting qualitative data: A field manual for applied research. Thousand Oaks, CA: SAGE.

Guthman, J. (2008). Bringing good food to others: Investigating the subjects of alternative food practice. Cultural G eographies, 15(4), 431-447. https:/ / doi.org/ 10.1177/ 14744744008094315

Hardesty, S. Feenstra, G., Visher, D ., Lerman T., Thilmany-McFadden D ., Bauman A... Rainbolt, G. N. (2014). Valuesbased supply chains: Supporting regional food and farms. E conomic D evelopment Quarterly, 28(1) 17-27. https:/ / doi.org/ 10.1177/ 0891242413507103

Hinrichs, C. C. (2000). Embeddedness and local food systems: Notes on two types of direct agricultural market. Journal of Rural Studies, 16(30), 295-303. https:/ / doi.org/ 10.1016/ S0743-0167(99)00063-7

Hinrichs, C. C. (2003). The practice and politics of food system localization. Journal of Rural Studies, 19(1), 33-45. https:/ / doi.org/ 10.1016/ S0743-0167(02)00040-2

Hoffman, J. A., Agrawal, T., Wirth, C., Watts, C., Adeduntan, G., Myles, L., \& Castaneda-Sceppa, C. (2012). Farm to family: Increasing access to affordable fruits and vegetables among urban Head Start families. Journal of $\mathrm{H}$ unger \& E nvironmental N utrition, 7(2-3), 165-177. https:/ / doi.org/ 10.1080/ 19320248.2012.703522

Hoffman, J. A., Schmidt, E. M., Wirth, C., Johnson, S., Sobell, S. A., Pelissier, K.,... Izumi, B. T. (2016). Farm to preschool: The state of the research literature and a snapshot of national practice. Journal of $H$ unger \& E nvironmental N utrition, 12(4), 443-465. Retrieved from https:/ / doi.org/ 10.1080/ 19320248.2016.1227747

Izumi, B. T., Wright, D. W., \& Hamm, M. W. (2010a). Farm to school programs: Exploring the role of regionally-based food distributors in alternative agrifood networks. A griculture and $\mathrm{H}$ uman $\mathrm{V}$ alues, 27(3), 335-350.

https:/ / doi.org/ 10.1007/ s10460-009-9221-x

Izumi, B. T., Wright, D. W., \& Hamm M. W. (2010b). Market diversification and social benefits: Motivations of farmers participating in farm to school programs. Journal of Rural Studies, 26(4), 374-382.

https:// doi.org/ 10.1016/j.jrurstud.2010.02.002

Izumi, B. T., Alaimo, K., \& Hamm, M.W. (2010c). Farm-to-school programs: Perspectives of school food service professionals. Journal of N utrition E ducation \& Behavior, 42 (2), 83-91. https:/ / doi.org/ 10.1016/ j.jneb.2008.09.003 
Journal of Agriculture, Food Systems, and Community Development

ISSN: 2152-0801 online

https:/ / www.foodsystemsjournal.org

Izumi, B. T., Eckhardt, C. L., Hallman, J. A., Herro, K., \& Barberis, D . A. (2015). Harvest for healthy kids pilot study: Associations between exposure to a farm-to-preschool intervention and willingness to try and liking of target fruits and vegetables among low-income children in head start. Journal of the A cademy of $\mathrm{N}$ utrition and D ietetics, 115(12), 2003-2013. https:// doi.org/ 10.1016/ j.jand.2015.07.020

Joshi, A., Azuma, A. M., \& Feenstra, G . (2008). D o farm-to-school programs make a difference? Findings and future research needs. Journal of $\mathrm{H}$ unger \& E nvironmental $\mathrm{N}$ utrition, 3(2-3), 229-246. https:/ / doi.org/ 10.1080/ 19320240802244025

Kirwan, J. (2004). Alternative strategies in the UK agro-food system: Interrogating the alterity of farmers' markets. Sociologia Ruralis, 44(4), 395-414. https:/ / doi.org/ 10.1111/ j.1467-9523.2004.00283.x

Kline, A. (2015). L ocal foods in the child and adult care food program with questions and answers. (Memo CACFP 11-2015). Alexandria, VA: U.S. D epartment of Agriculture, Food and Nutrition Service. Retrieved from https:/ / fnsprod.azureedge.net/ sites/default/ files/ cacfp/CACFP11_2015os.pdf

Low, S. A., A dalja, A., Beaulieu, E., Key, N., Martinez, S., Melton, A.,... Jablonski, B. B. R. (2015). Trends in U.S. local and regional food systems: A report to Congress. Economic Research Service, USD A. Retrieved from https:/ / www.ers.usda.gov/ webdocs/ publications/42805/51173 ap068.pdf?v=42083

Mack, N., Woodsong, C., MacQueen, K., Guest, G., \& Namey, E. (2005). Q ualitative research methods: A data ollector's filed guide. Retrieved from https:/ / www.fhi360.org/ sites/ default/ files/ media/ documents/ Qualitative\%20Research\%20Methods\%20-\%20A\% 20Data\%20Collector\%27s\%20Field\%20G uide.pdf

Merriam, S. B. (1995) What can you tell from an $\mathrm{N}$ of 1 ? Issues of validity and reliability in qualitative research. PA A CE Journal of L ifelong L earning, 4, 51-60. Retrieved from https:/ / www.iup.edu/ WorkArea/ linkit.aspx?LinkIdentifier=id\&ItemID =18193

North Carolina Farm to Preschool Network. (2016). Reach for the stars with farm to childcare. Retrieved from http:/ / growing-minds.org/ documents/ reach-for-the-stars.pdf

O hmart, J. L. (2002). D irect mark eting to schools: A new opportunity for family farmers. Davis: University of California Sustainable Agriculture Research \& Education Program and the Agricultural Sustainability Institute at University of California, D avis. Retrieved from http:/ / asi.ucdavis.edu/ programs/ sarep/ publications/ food-andsociety/ directmarketing-schools-2002.pdf

Poppendieck, J. (2010). F ree for all: Fix ing school food in A merica. Berkeley: University of California Press.

Saldaña, J. (2009). The oding manual for qualitative researchers. Thousand O aks, CA: SAGE.

Schafft K., Hinrichs, C. C., \& Bloom, J. D . (2010) Pennsylvania farm-to-school programs and the articulation of local context. Journal of $\mathrm{H}$ unger \& E nvironmental $N$ utrition, 5(1), 23-40. https:/ / doi.org/ 10.1080/ 19320240903574155

Stephens, L. \& O berholtzer, L. (2016). Results from the 2015 national survey of early care and education providers: L ocal procurement, gardening, and food and farm education. National Farm to School Network. Retrieved from http:/ / www.farmtoschool.org/ Resources/ ECESurvey Report.pdf

Stevenson, G. W. \& Pirog, R. (2008). Values-based supply chains: Strategies for agrifood enterprises of the middle. In T. A. Lyson, G. W. Stevenson, \& R. Welsch (Eds.), F ood and the mid-level farm: Renewing an agriculture of the middle (p. 119146). Cambridge, MA: MIT Press.

Story, M. P. D ., Kaphingst, K. M., \& French, S. (2006). The role of schools in obesity prevention. The Future of Children, 16(1), 109-142. https:/ / doi.org/ 10.1353/ foc.2006.0007

Thornburg, G. K. (2013). Embeddedness, marketness, and economic instrumentalism in the O klahoma farm-to-school program. Journal of Rural and C ommunity D evelopment, 8(3), 321-334. Retrieved from http:/ / joumals.brandonu.ca/ jrcd/ article/ download/ 1035/ 252

Williams, P. A., Cates, S. C., Blitstein, J. L., Hersey, J., Gabor, V., Ball, M... Singh, A. (2014). Nutrition-education program improves preschoolers' at-home diet: A group randomized trial. Journal of the A cademy of $\mathrm{N}$ utrition and D ietetics, 114 (7), 1001-1008. https:/ / doi.org/ 10.1016/ j.jand.2014.01.015

Winter, M. (2003). Embeddedness, the new food economy and defensive localism. Journal of Rural Studies, 19(1), 23-32. https:/ / doi.org/ 10.1016/ S0743-0167(02)00053-0

Yin, R. K. (2009). C ase study research: D esign and methods (4th ed.). Thousand O aks, CA: SAGE. 